\begin{tabular}{|c|l|}
\hline Title & Dielectric properties of anodic films on sputter-deposited Ti-Si porous columnar films \\
\hline Author(s) & Tanvir, M. Tauseef; Fujii, T.; A oki, Y.; Fushimi, K.; Habazaki, H. \\
\hline Citation & $\begin{array}{l}\text { A pplied Surface Science, 257(19), 8295-8300 } \\
\text { https://doi.org/10.1016/.apsusc.2011.01.036 }\end{array}$ \\
\hline Issue Date & 2011-07-15 \\
\hline Doc URL & http://hdl.handle.net/2115/47411 \\
\hline Type & article (author version) \\
\hline File Information & A SS257_8295-8300.pdf \\
\hline
\end{tabular}

Instructions for use 


\title{
Dielectric Properties of Anodic Films on Sputter-Deposited Ti-Si Porous Columnar Films
}

\author{
M. Tauseef Tanvir ${ }^{1,2}$, T. Fujii ${ }^{1}$, Y. Aoki ${ }^{1}$, K. Fushimi $^{1}$, H. Habazaki ${ }^{1, *}$ \\ ${ }^{1}$ Division of Materials Chemistry, Faculty of Engineering, Hokkaido University, Sapporo 060- \\ 8628, Japan
}

${ }^{2}$ Pakistan Institute of Engineering and Applied Sciences (PIEAS), Islamabad 45650, Pakistan

*Corresponding author; Phone \& Fax:+81-11-706-6575, e-mail: habazaki@eng.hokudai.ac.jp

\begin{abstract}
For electrolytic capacitor application of the single-phase Ti alloys containing supersaturated silicon, which form anodic oxide films with superior dielectric properties, porous $\mathrm{Ti}-7 \mathrm{at} \% \mathrm{Si}$ columnar films, as well as Ti columnar films, have been prepared by oblique angle magnetron sputtering on to aluminum substrate with a concave cell structure to enhance the surface area and hence capacitance. The deposited films of both $\mathrm{Ti}$ and Ti-7at $\%$ Si have isolated columnar morphology with each column revealing nanogranular texture. The distances between columns are $\sim 500 \mathrm{~nm}$, corresponding to the cell size of the textured substrate and the gaps between columns are $100-200 \mathrm{~nm}$. When the porous Ti-7 at $\% \mathrm{Si}$ film is anodized at a constant current density in ammonium pentaborate electrolyte, the growth of a uniform amorphous oxide film continues to $\sim 35 \mathrm{~V}$, while it is limited to less than $6 \mathrm{~V}$ on the porous Ti film. The maximum voltage of the growth of uniform amorphous oxide films on the Ti-7 at $\%$ Si films is similar for
\end{abstract}


both the flat and porous columnar films, suggesting little influence of surface roughness on the amorphous-to-crystalline transition of growing anodic oxide under the high electric field. Due to the suppression of crystallization to sufficiently high voltages, the anodic oxide films formed on the porous Ti-7 at \% Si film shows markedly improved dielectric properties, in comparison with those on the porous Ti film.

Keywords: Porous deposits, Non-equilibrium alloy, Oblique angle deposition, Anodic oxide, Dielectric

\section{Introduction}

Titanium and its alloys are an important member of engineering materials with light weight, high weight-to-strength ratio, biocompatibility and high corrosion resistance even in very aggressive environments. The oxide formed on titanium is an n-type semiconductor with many attractive properties. The thickness of a native oxide film on titanium at ambient temperature is only a few nm, but can be increased greatly by anodizing in suitable electrolytes.

The anodic oxide films on valve metals are important dielectric materials. In fact, those on aluminum and tantalum have been used widely in electrolytic capacitors. Tantalum capacitors play a major role in passive components industry, due to their high reliability, excellent volumetric efficiency and low equivalent series resistance [1]. However, due to limitation of natural resources of tantalum and a strong demand of further increase in capacitance, the industry is seeking new materials with higher permittivity, which are composed of abundant elements. 
Titanium dioxide has high permittivity $\left(\varepsilon_{\mathrm{ox}}=40 \sim 120\right)$ and is a promising dielectric oxide for electrolytic capacitors [2]. However, anodizing of titanium results readily in an amorphousto-crystalline transition at low formation voltages [2-7]. After crystallization of the anodic oxide, film growth accompanies oxygen gas generation, introducing a high density of flaws in the developed anodic oxide films $[3,7]$. Thus, an amorphous-to-crystalline transition must be avoided for the formation of dielectric oxide suitable for capacitor application.

Recently, effective suppression of crystallization of anodic $\mathrm{TiO}_{2}$ has been demonstrated by incorporation of silicon species from metal substrate, i.e., a Ti-6 at $\%$ Si alloy [7-9]. Alloying of titanium with other metals, such as aluminum [7], molybdenum [10, 11], niobium [12], tungsten [13] and zirconium [14, 15], is also effective, although higher concentrations of alloying elements, compared with silicon addition, are required to form amorphous oxide without crystallization to voltages higher than $100 \mathrm{~V}$.

For capacitor application of the Ti alloys that form flaw-free anodic oxide films, porous alloy films with high surface areas must be tailored to enhance the capacitance, since the capacitance, $C$, is proportional to surface area, $S$, as follows,

$$
C=\varepsilon_{0} \varepsilon_{o x} S / d
$$

in which, $\varepsilon_{0}$ is the permittivity of vacuum, $\varepsilon_{\mathrm{Ox}}$ is the relative permittivity of oxide and $d$ is the thickness of oxide film. In tantalum electrolytic capacitors, a high-temperature sintering process has been utilized to produce porous tantalum anode with high surface area. However, such hightemperature process is not applicable for the Ti-Si alloy system, since the solubility of silicon to titanium is limited to less than 1 at $\%$ at equilibrium [16]. 
In the present study, oblique angle magnetron sputtering has been used as an alternative approach for fabrication of single-phase porous alloy films supersaturated with alloying element. Oblique angle deposition (OAD) is one of the useful and attractive physical vapor deposition techniques to tailor porous films with tilted isolated columnar structure [17]. The porosity is generated due to a self-shadowing effect and limited surface diffusion of adatoms. Recently, it has been reported that controlled rotation of substrate during OAD enables to create sculptured micro- and nano-structured thin films, such as nanopillars [18-23], zig-zag [24-27], nanospirals $[28,29]$ and Y-shape [30] columns. This advanced technique, often referred to as glancing angle deposition, allows us to develop a range of engineered micro- and nano-structures $[17,31]$. However, complex substrate rotation during deposition is not suitable for the production of capacitor anode because it limits the production rate of the anode. The authors have recently reported that the utilization of a substrate with regular concave cell structure is effective in enhancing the shadow effect in OAD and thus in fabrication of isolated columnar films [32-34].

In this work, we have deposited $\mathrm{Ti}$ and $\mathrm{Ti}-7 \mathrm{at} \% \mathrm{Si}$ isolated columnar films by oblique angle magnetron sputtering on to the substrate with a concave cell structure. The anodic oxide films are grown on the porous metallic films in ammonium pentaborate electrolyte, and their dielectric properties are examined. The composition of Ti-7 at $\%$ Si has been selected since further increase in silicon content decreases the capacitance as a consequence of incorporation of an increased amount of silicon species that reduces the permittivity of oxide [35].

\section{Experimental}


Thin porous films of Ti-7 at.\% Si were prepared by magnetron sputtering at an oblique angle of $85^{\circ}$, with respect to the substrate normal, on to textured aluminum substrate for $3.6 \mathrm{ks}$, using a target consisting of $99.9 \%$ titanium disk of $100 \mathrm{~mm}$ in diameter and silicon pieces of 20 $\mathrm{mm}$ square, with the latter placed symmetrically on the erosion region of the former disk. The substrate holders were rotated along the chamber axis and its own axis to get alloy films of uniform thickness and composition. The porous Ti films were also prepared under the same condition using Si-free target. The Ti and Ti-7 at $\%$ Si films with flat surfaces were also deposited on flat glass substrate at an angle of $0^{\circ}$ (the substrate surface is parallel to the target surface). The structures of the deposits were identified by grazing incidence X-ray diffraction (incident angle of $\mathrm{X}$-ray $=2^{\circ}$ ) using $\mathrm{Cu} \mathrm{K} \alpha$ radiation. Surface and cross-sections of deposits were observed by a JEOL JSM-6500F field emission scanning electron microscope (SEM) operated at $5 \mathrm{kV}$.

The textured aluminum substrate was prepared as in our previous reports [33, 34]. Briefly, high purity aluminum sheet was anodized at $195 \mathrm{~V}$ in $0.3 \mathrm{~mol} \mathrm{dm}^{-3}$ phosphoric acid electrolyte at $278 \mathrm{~K}$ for $1.8 \mathrm{ks}$, followed by chemical dissolution of the resultant porous anodic film in a mixed solution of chromic acid-phosphoric acid at $333 \mathrm{~K}$.

The deposited films were anodized at a constant current density of $10 \mathrm{~A} \mathrm{~m}^{-2}$, relative to the apparent geometrical surface area, up to $50 \mathrm{~V}$ in stirred $0.1 \mathrm{~mol} \mathrm{dm}^{-3}$ ammonium pentaborate electrolyte at $293 \mathrm{~K}$. Two-electrode cell with a platinum counter electrode was used for the galvanostatic anodizing. In addition, potentiostatic anodizing of the deposited films were carried out in the same electrolyte for $1.8 \mathrm{ks}$ between $2 \mathrm{~V}$ and $10 \mathrm{~V}$. In this case a three-electrode cell with $\mathrm{Ag} / \mathrm{AgCl}$ reference electrode was used. In this paper all potentials for potentiostatic anodizing were referred to this electrode. The electrochemical impedance spectroscopy (EIS) 
was used to evaluate the dielectric properties of the anodic films formed as well as the surface roughness. The EIS data were obtained by applying $20 \mathrm{mV}$ ac signal amplitude in the frequency range of 0.01-10 kHz using Solartron SI 1287 potentiostat/galvanostat and Solartron 1255B frequency response analyzer. The leakage current density, defined as the current density recorded after application of $70 \%$ of the formation voltage for $120 \mathrm{~s}$, was also measured in $0.1 \mathrm{~mol} \mathrm{dm}^{-3}$ ammonium pentaborate electrolyte.

\section{Results and Discussion}

\subsection{Morphology and phases of deposits}

SEM images of the Ti and Ti-7 at\% Si films deposited on textured substrate (Fig. 1) reveal porous nature with the size of pores between neighboring columns being 100-200 nm. The films have isolated columnar morphology with the column diameter of $300-400 \mathrm{~nm}$ and the column-to-column distance is $\sim 500 \mathrm{~nm}$, which is in agreement with the cell size of substrate. The thickness of the columnar films is $\sim 600 \mathrm{~nm}$. Due to an incidence of deposited atoms from the right-hand side of the micrographs, the columns obtained are tilted at an angle of $28-30^{\circ}$ from substrate normal to the right-hand side. The smaller tilted angle of deposits, compared with the incident angle, is usual in the oblique angle deposition $[31,36]$. The deposition occurs mainly on substrate cell walls faced on the incident direction, while the deposition is limited in the opposite faces due to a shadowing effect, such that isolated columns are developed on the cellular substrate. However, a thin deposit layer, 50-100 nm thick, is present between columns, covering the entire substrate surface with either Ti or Ti-7 at $\%$ Si layer. The surface appearance of the Ti 
and Ti-7 at $\%$ Si deposits is similar, and both columns reveal granular morphology. This is contrast to the different morphologies found between the $\mathrm{Nb}$ columns that show subcolumnar morphology and the amorphous Nb-Si columns with smooth columns surface [34]. Similar column morphology for both $\mathrm{Ti}$ and $\mathrm{Ti}-7 \mathrm{at} \% \mathrm{Si}$ deposits arises from the fact that both deposits consist of an hcp phase (Fig. 2). Although the diffraction intensities for the Ti-7 at $\%$ Si are weak, 002 and 103 lines are clearly detected. The absence of other diffraction lines suggests possible preferred orientation of deposits, as is often found in PVD films.

\subsection{Growth of anodic titanium oxide}

Fig. 3 shows the voltage-time responses during anodizing the flat and porous films of Ti and $\mathrm{Ti}-7$ at $\% \mathrm{Si}$ alloy. The deposited films were anodized galvanostatically at a constant current density of $10 \mathrm{~A} \mathrm{~m}^{-2}$ in $0.1 \mathrm{~mol} \mathrm{dm}^{-3}$ ammonium pentaborate electrolyte at $293 \mathrm{~K}$. The formation voltage increases linearly only up to $\sim 5 \mathrm{~V}$ for flat and porous Ti films. The reduced slope for the porous Ti film is associated with the increased surface area. Then, both the Ti films show the same constant voltage of $8 \mathrm{~V}$, during which gas, probably oxygen, was evolved on the specimen surface. It is known that the gas evolution occurs after crystallization of anodic titanium oxide [7], because of introduction of an electron-conducting path in the anodic oxide film [3]. Thus, the crystallization on the Ti films should occur at $\sim 5 \mathrm{~V}$ in the present anodizing condition. Such a low crystallization voltage is in agreement with previous reports $[4,6]$.

In contrast to the $\mathrm{Ti}$ films, the flat $\mathrm{Ti}-7 \mathrm{at} \% \mathrm{Si}$ film reveals a linear voltage rise up to $\sim 35$ $\mathrm{V}$, indicating growth of amorphous oxide to the high voltage by suppressing nucleation of crystalline oxide. Following the linear voltage rise, the slope increases gradually to $72 \mathrm{~V}$, at 
which a sudden drop of voltage is observed. The gradual slope rise is an evidence of nucleation of crystalline oxide and subsequent generation of oxygen gas, which is trapped as gas bubbles in the anodic oxide film [7]. The anodic oxide films formed on the Ti-Si alloys consist of two layers, comprising an outer silicon-free $\mathrm{TiO}_{2}$ layer and an inner layer containing both units of $\mathrm{TiO}_{2}$ and $\mathrm{SiO}_{2}[7-9,35]$. Such two-layered anodic oxide films are formed by simultaneous migrations of $\mathrm{Ti}^{4+}$ ions outwards and $\mathrm{O}^{2-}$ ions inwards with the silicon species being immobile $[8,9]$. Thus, the outer layer, formed at the film/electrolyte interface by migration of $\mathrm{Ti}^{4+}$ ions outwards, is silicon free and the remaining inner layer contains silicon species due to the formation of film material at the alloy/film interface by migration of $\mathrm{O}^{2-}$ ions inwards. The crystalline oxide nucleates at the boundary between the outer layer and the inner layer of the anodic oxide films, since an airformed oxide, present before anodizing, acts as a nucleation site of crystalline oxide [7]. Due to generation of gas bubbles, which increase ionic resistivity of growing anodic oxide, the rate of voltage rise increases gradually. The sudden drop of the voltage at $72 \mathrm{~V}$ is associated with the rupture of the anodic film due to increased gas pressure in gas bubbles formed.

The initial slope for the porous $\mathrm{Ti}-7 \mathrm{at} \% \mathrm{Si}$ film is rather low, due to increased surface area. The slope increases gradually to $4 \mathrm{~V}$, probably due to reduction of the surface area. Narrow gaps present on the granular Ti-7 at\% Si columns may be filled with oxide, due to high PillingBedworth ratio of 1.93 for $\mathrm{Ti} / \mathrm{TiO}_{2}$ [37]. The wider gaps of 100-200 $\mathrm{nm}$ between columns are still present, such that a linear voltage rise appears between 4 and $35 \mathrm{~V}$. During this linear voltage rise, bubble-free amorphous anodic oxide should be formed. Then, the slope is reduced and the voltage becomes constant at $44 \mathrm{~V}$, at which gas evolution has been visible to the naked eye. The absence of gradual slope rise on the porous Ti-7 at $\% \mathrm{Si}$ film suggests easier rupture of the anodic film formed on the columnar substrate. Compared with a flat substrate, more tensile 
stress may be applied at the convex region of the columnar film. Further, due to a wider area of the film/electrolyte interface, compared with the alloy/film interface at the convex region, the relative thickness of the outer silicon-free layer in anodic oxide film should be reduced. Under such situation, it is likely that the rupture of anodic oxide films occurs more readily on the columnar film, compared with the flat one.

The more important finding is that the maximum voltage, to which a linear voltage rise continues, is almost the same for both the flat and porous Ti-7 at $\% \mathrm{Si}$. This fact may indicate the negligible influence of growth stress on the nucleation of crystalline oxide during growth of anodic oxide. This fact is important for practical application of porous Ti-Si alloys for anode of electrolytic capacitor; even on the porous substrate with a high surface area, it is possible to grow uniform amorphous dielectric oxide films to sufficiently high voltages without crystallization.

Next, we anodized the porous $\mathrm{Ti}$ and $\mathrm{Ti}-7 \mathrm{at} \% \mathrm{Si}$ columnar films potentiostatically in a potential range of 2 to $10 \mathrm{~V}$ for $1.8 \mathrm{ks}$ to examine the dielectric properties of the anodic oxide films. Fig. 4 shows the final current density during anodizing as a function of formation voltage. The current density increases largely at and above $6 \mathrm{~V}$ for the Ti film, due to film crystallization and associated gas evolution. In contrast, the porous Ti-7 at $\%$ Si film reveals the current densities less than $0.04 \mathrm{~A} \mathrm{~m}^{-2}$ up to $10 \mathrm{~V}$, suggesting no crystallization of oxide and oxygen gas generation under potentiostatic anodizing. Additionally, during potentiostatic anodizing, the logarithm of current decreased linearly with the logarithm of anodizing time at a slope of almost -1 at all potentials up to $10 \mathrm{~V}$ for the porous Ti-7 at $\%$ Si film, indicating high growth efficiency of anodic oxide close to $100 \%$. 


\subsection{Electric Properties}

Capacitance measurements of potentiostatically formed anodic oxide films on the porous Ti and Ti-Si alloy were carried out in $0.1 \mathrm{~mol} \mathrm{dm}^{-3}$ ammonium pentaborate solution. The obtained Bode diagrams for the porous $\mathrm{Ti}$ and $\mathrm{Ti}-7$ at $\% \mathrm{Si}$ films are shown in Fig. 5. The Ti specimens anodized at voltages up to $6 \mathrm{~V}$ reveal a slope of impedance close to -1 and phase shift of nearly $-90^{\circ}$ in a frequency range of less than $100 \mathrm{~Hz}$., typical of dielectric materials. However, at 8 and $10 \mathrm{~V}$, the impedance slope deviates from -1 at less than $10 \mathrm{~Hz}$, along with the deviation of phase shift from $-90^{\circ}$ since the formation voltages are above the breakdown, i.e., crystallization, voltage. In contrast, Bode diagrams that are typical for dielectric materials are obtained for the Ti-7 at\% Si films at all the formation voltages examined (Fig. 5(b)). From the analysis of the Bode diagrams of the anodized Ti-7 at $\%$ Si films as in the case of previously reported anodized porous $\mathrm{Nb}-\mathrm{Si}$ columnar films [34], the capacitance of the anodic oxide films were obtained.

Fig. 6 shows the correlation between the reciprocal capacitance of the anodic films and formation voltage for the flat and porous $\mathrm{Ti}-7 \mathrm{at} \% \mathrm{Si}$ films. A linear correlation is observed for the flat alloy film, as expected from the equation (1), since the thickness of anodic films changes linearly with the formation voltage. The higher capacitances of the anodic films formed on the porous alloy film is evident at all formation voltages. The slope for the porous alloy film changes at $4 \mathrm{~V}$, in agreement with the slope change in the voltage-time response during galvanostatic anodizing (Fig. 3). The enhanced reduction of capacitance above $4 \mathrm{~V}$ should be again the reduced surface area by filling the narrow gaps in the granular columns. The capacitances of the anodic films on the porous alloy film are 3.5 and 2.7 times those on the respective flat alloy film 
at 2 and $10 \mathrm{~V}$, respectively. It is predicted that the capacitance will be further enhanced approximately linearly with length of columns by longer deposition.

A striking effect of silicon addition appears on the leakage current, as shown in Fig. 7. The leakage current of the porous Ti-Si alloy films is $\sim 2 \mathrm{~mA} \mathrm{~m}^{-2}$ at all the formation voltages up to $10 \mathrm{~V}$. In contrast, the leakage current of the porous titanium is $10 \mathrm{~mA} \mathrm{~m}^{-2}$ even at $2 \mathrm{~V}$ and increases markedly with an increase in voltage. Dielectric loss $(\tan \delta)$ of the anodized specimens

(Fig. 8) also becomes low by the addition of silicon. The dielectric loss for the silicon-containing specimens decreases with formation voltage, leading to development of reliable dielectric material for capacitors with high surface area.

\section{Conclusions}

In summary, the present work demonstrates the high potential of the single phase porous Ti-Si alloy containing supersaturated silicon as a capacitor material. The porous isolated columnar alloy films are prepared successfully by oblique angle magnetron sputtering on to aluminum substrate with a regular concave cell structure. Crystallization of anodic oxide during anodizing, which is detrimental for capacitor application, is effectively suppressed by silicon addition, even on the porous alloy substrate. Negligible influence of surface roughness on the crystallization of anodic oxide is found in this study. Thus, uniform anodic oxide films can grow to sufficiently high voltages for capacitor application. Due to suppression of crystallization, leakage current density as well as dielectric loss of anodic oxide films is markedly reduced by the addition of silicon. 


\section{Acknowledgements}

The present work was supported in part by Global COE Program (Project No. B01: Catalysis as the Basis for Innovation in Materials Science).

\section{References}

[1] J.D. Prymak, New tantalum capacitors in power supply applications, in: 1998 IEEE Ind. Appl. Soc. Annual Meeting IEEE, 1998, pp. 1129-1137.

[2] A. Aladjem, Anodic oxidation of titanium and its alloys, J. Mater. Sci., 8 (1973) 688-704.

[3] C.K. Dyer, J.S.L. Leach, Breakdown and efficiency of anodic oxide growth on titanium, J. Electrochem. Soc., 125 (1978) 1032.

[4] T. Ohtsuka, J. Guo, N. Sato, Raman spectra of the anodic oxide film on titanium in acidic sulfate and neutral phosphate solutions, J. Electrochem. Soc., 133 (1986) 2473.

[5] A. Felske, W.J. Plieth, Raman spectroscopy of titanium dioxide layers, Electrochim. Acta, 34 (1989) 75-77.

[6] T. Shibata, Y.-C. Zhu, The effect of film formation conditions on the structure and composition of anodic oxide films on titanium, Corros. Sci., 37 (1995) 253-270.

[7] H. Habazaki, M. Uozumi, H. Konno, K. Shimizu, P. Skeldon, G.E. Thompson, Crystallization of anodic titania on titanium and its alloys, Corros. Sci., 45 (2003) 20632073. 
[8] H. Habazaki, K. Shimizu, S. Nagata, P. Skeldon, G.E. Thompson, G.C. Wood, Ionic transport in amorphous anodic titania stabilised by incorporation of silicon species, Corros. Sci., 44 (2002) 1047-1055.

[9] H. Habazaki, K. Shimizu, S. Nagata, P. Skeldon, G.E. Thompson, G.C. Wood, Ionic mobilities in amorphous anodic titania, J. Electrochem. Soc., 149 (2002) B70-B74.

[10] H. Habazaki, M. Uozumi, H. Konno, K. Shimizu, S. Nagata, K. Asami, P. Skeldon, G.E. Thompson, Influence of molybdenum species on growth of anodic titania, Electrochim. Acta, 47 (2002) 3837-3845.

[11] H. Habazaki, M. Uozumi, H. Konno, S. Nagata, K. Shimizu, Formation of barrier-type amorphous anodic films on Ti-Mo alloys, Surf. Coat. Technol., 169 (2003) 151-154.

[12] H. Habazaki, H. Konno, K.-i. Shimizu, Structure and growth behavior of anodic oxide films on titanium and its alloys, J. Surf. Finish. Soc. Jpn., 54 (2003) 456-461.

[13] H. Habazaki, K. Takahiro, S. Yamaguchi, K. Shimizu, P. Skeldon, G.E. Thompson, G.C. Wood, Influence of tungsten species on the structure of anodic titania, Phil. Mag. A, 78 (1998) 171-187.

[14] H. Habazaki, M. Uozumi, H. Konno, K. Shimizu, S. Nagata, K. Asami, K. Matsumoto, K. Takayama, Y. Oda, P. Skeldon, G.E. Thompson, Influences of structure and composition on growth of anodic oxide films on Ti-Zr alloys, Electrochim. Acta, 48 (2003) 3257-3266.

[15] H. Habazaki, K. Shimizu, S. Nagata, K. Asami, K. Takayama, Y. Oda, P. Skeldon, G.E. Thompson, Inter-relationship between structure and dielectric properties of crystalline anodic zirconia, Thin Solid Films, 479 (2005) 144-151.

[16] T.B. Massalski, Binary Alloy Phase Diagrams ASM International, 1990. 
[17] J.J. Steele, M.J. Brett, Nanostructure engineering in porous columnar thin films: recent advances, J. Mater. Sci. Mater. Elect., 18 (2007) 367-379.

[18] C.M. Zhou, D. Gall, Competitive growth of Ta nanopillars during glancing angle deposition: Effect of surface diffusion, J. Vac. Sci. Technol., A, 25 (2007) 312-318.

[19] C.M. Zhou, D. Gall, The structure of Ta nanopillars grown by glancing angle deposition, Thin Solid Films, 515 (2006) 1223-1227.

[20] M. Malac, R.F. Egerton, Observations of the microscopic growth mechanism of pillars and helices formed by glancing-angle thin-film deposition, J. Vac. Sci. Technol., A, 19 (2001) 158-166.

[21] M. Malac, R.F. Egerton, M.J. Brett, B. Dick, Fabrication of submicrometer regular arrays of pillars and helices, J. Vac. Sci. Technol. B, 17 (1999) 2671-2674.

[22] K. Robbie, C. Shafai, M.J. Brett, Thin films with nanometer-scale pillar microstructure, J. Mater. Res., 14 (1999) 3158-3163.

[23] B. Dick, M.J. Brett, T. Smy, Controlled growth of periodic pillars by glancing angle deposition, J. Vac. Sci. Technol. B, 21 (2003) 23-28.

[24] K. Robbie, M.J. Brett, Sculptured thin films and glancing angle deposition: Growth mechanics and applications, J. Vac. Sci. Technol. A, 15 (1997) 1460-1465.

[25] M. Suzuki, T. Ito, Y. Taga, Photocatalysis of sculptured thin films of TiO2, Appl. Phys. Lett., 78 (2001) 3968-3970.

[26] J. Lintymer, N. Martin, J.M. Chappe, P. Delobelle, J. Takadoum, Influence of zigzag microstructure on mechanical and electrical properties of chromium multilayered thin films, Surf. Coat. Technol., 180-81 (2004) 26-32. 
[27] R. Messier, V.C. Venugopal, P.D. Sunal, Origin and evolution of sculptured thin films, J. Vac. Sci. Technol., A, 18 (2000) 1538-1545.

[28] O. Toader, S. John, Proposed square spiral microfabrication architecture for large threedimensional photonic band gap crystals, Science, 292 (2001) 1133-1135.

[29] S.R. Kennedy, M.J. Brett, O. Toader, S. John, Fabrication of tetragonal square spiral photonic crystals, Nano Lett., 2 (2002) 59-62.

[30] J. Wang, H.C. Huang, S.V. Kesapragada, D. Gall, Growth of Y-shaped nanorods through physical vapor deposition, Nano Lett., 5 (2005) 2505-2508.

[31] M.M. Hawkeye, M.J. Brett, Glancing angle deposition: Fabrication, properties, and applications of micro- and nanostructured thin films, J. Vac. Sci. Technol., A, 25 (2007) $1317-1335$.

[32] M.T. Tanvir, K. Fushimi, Y. Aoki, H. Habazaki, Oblique angle deposition of columnar niobium films for capacitor application, Mater. Trans., 49 (2008) 1320-1326.

[33] M. Tauseef Tanvir, Y. Aoki, H. Habazaki, Formation of porous niobium films by oblique angle deposition: Influence of substrate morphology, Thin Solid Films, 517 (2009) 67116716.

[34] M.T. Tanvir, Y. Aoki, H. Habazaki, Improved electrical properties of silicon-incorporated anodic niobium oxide formed on porous Nb-Si substrate, Appl. Surf. Sci., 255 (2009) 8383-8389.

[35] M.T. Tanvir, K. Fushimi, K. Shimizu, S. Nagata, P. Skeldon, G.E. Thompson, H. Habazaki, Influence of silicon on the growth of barrier-type anodic films on titanium, Electrochim. Acta, 52 (2007) 6834-6840. 
[36] R.N. Tait, T. Smy, M.J. Brett, Modelling and characterization of columnar growth in evaporated films Thin Solid Films, 226 (1993) 196.

[37] J.P.S. Pringle, The anodic oxidation of superimposed metallic layers: theory, Electrochim. Acta, 25 (1980) 1423-1437. 
Figure captions

Fig. 1 Scanning electron micrographs of the sputter-deposited (a,c) Ti and (b,d) Ti-7 at $\% \mathrm{Si}$ columnar films. $(a, b)$ Surface images and $(c, d)$ fractured cross-sectional images.

Fig. 2 X-ray diffraction patterns of the sputter-deposited Ti and Ti-7 at\% Si columnar films.

Fig. 3 Voltage-time curves of the sputter-deposited Ti and Ti-7 at $\%$ Si flat and columnar films during anodizing at a constant current density of $10 \mathrm{~A} \mathrm{~m}^{-2}$ in $0.1 \mathrm{~mol} \mathrm{dm}^{-3}$ ammonium pentaborate electrolyte at $293 \mathrm{~K}$.

Fig. 4 Change in the final current density with formation voltage for the sputter-deposited Ti and Ti-7 at $\%$ Si columnar films during anodizing at several formation voltages in $0.1 \mathrm{~mol} \mathrm{dm}^{-3}$ ammonium pentaborate electrolyte at $293 \mathrm{~K}$ for $1.8 \mathrm{ks}$.

Fig. 5 Bode diagrams of the sputter-deposited (a) Ti and (b) Ti-7 at\% Si columnar films anodized at several formation voltages in $0.1 \mathrm{~mol} \mathrm{dm}^{-3}$ ammonium pentaborate electrolyte at 293 $\mathrm{K}$ for $1.8 \mathrm{ks}$. The diagrams were obtained in $0.1 \mathrm{~mol} \mathrm{dm}^{-3}$ ammonium pentaborate electrolyte at $283 \mathrm{~K}$

Fig. 6 Correlation between the formation voltage and the reciprocal of capacitance of the anodic films formed on the sputter-deposited Ti-7 at $\%$ Si flat and columnar films in $0.1 \mathrm{~mol} \mathrm{dm}^{-3}$ ammonium pentaborate electrolyte at $293 \mathrm{~K}$ for $1.8 \mathrm{ks}$.

Fig. 7 Change in the leakage current density with formation voltage for the sputter-deposited Ti and Ti-7 at $\%$ Si columnar films anodized at several formation voltages in $0.1 \mathrm{~mol} \mathrm{dm}^{-3}$ ammonium pentaborate electrolyte at $293 \mathrm{~K}$ for $1.8 \mathrm{ks}$. The leakage current density was 
measured at $70 \%$ of the formation voltage in $0.1 \mathrm{~mol} \mathrm{dm}^{-3}$ ammonium pentaborate electrolyte at $293 \mathrm{~K}$.

Fig. 8 Change in dielectric loss $(\tan \delta)$ with formation voltage for the sputter-deposited Ti and Ti-7 at $\%$ Si columnar films anodized at several formation voltages in $0.1 \mathrm{~mol} \mathrm{dm}^{-3}$ ammonium pentaborate electrolyte at $293 \mathrm{~K}$ for $1.8 \mathrm{ks}$. 

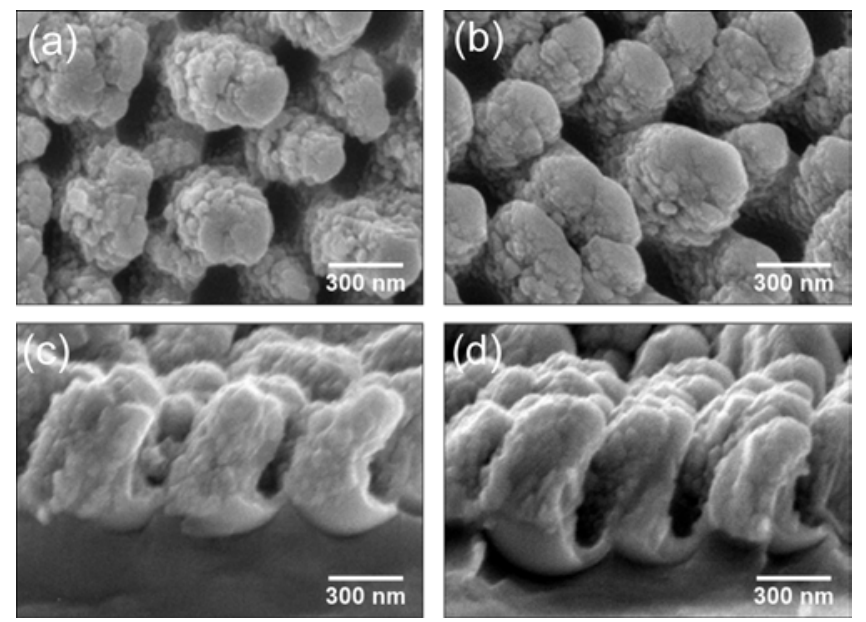

Fig. 1 Scanning electron micrographs of the sputter-deposited (a,c) Ti and (b,d) Ti-7 at\% Si columnar films. (a,b) Surface images and (c,d) fractured cross-sectional images. 


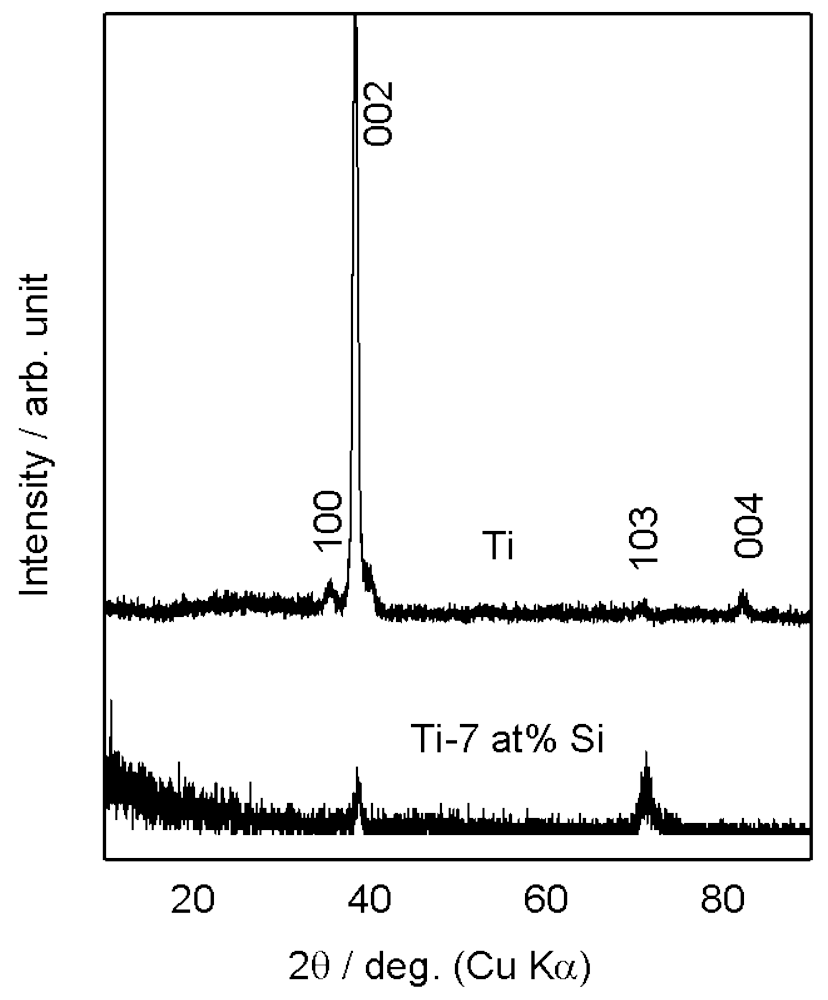

Fig. 2 X-ray diffraction patterns of the sputter-deposited Ti and Ti-7 at\% Si columnar films. 


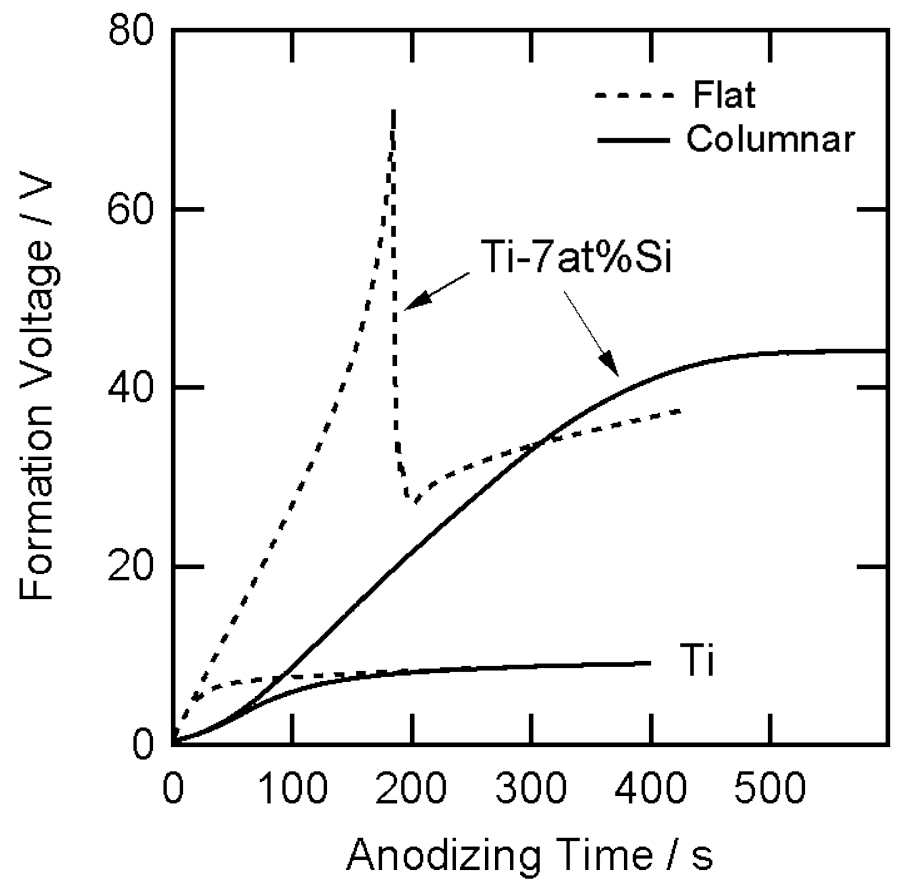

Fig. 3 Voltage-time curves of the sputter-deposited $\mathrm{Ti}$ and Ti-7 at\% Si flat and columnar films during anodizing at a constant current density of $10 \mathrm{~A} \mathrm{~m}^{-2}$ in $0.1 \mathrm{~mol} \mathrm{dm}^{-3}$ ammonium pentaborate electrolyte at $293 \mathrm{~K}$. 


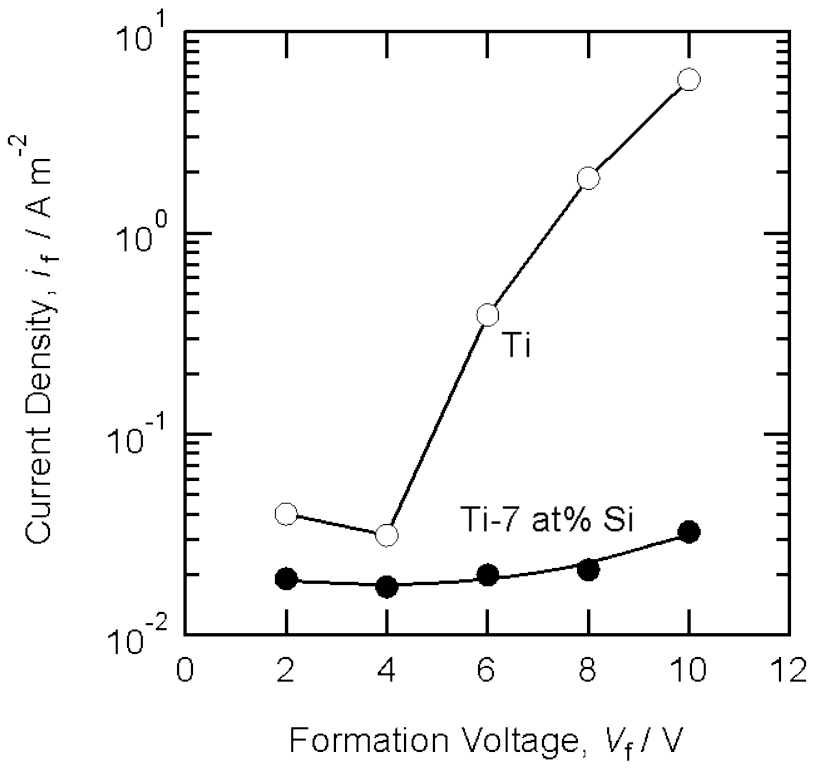

Fig. 4 Change in the final current density with formation voltage for the sputter-deposited Ti and Ti-7 at\% Si columnar films during anodizing at several formation voltages in $0.1 \mathrm{~mol} \mathrm{dm}^{-3}$ ammonium pentaborate electrolyte at $293 \mathrm{~K}$ for $1.8 \mathrm{ks}$. 

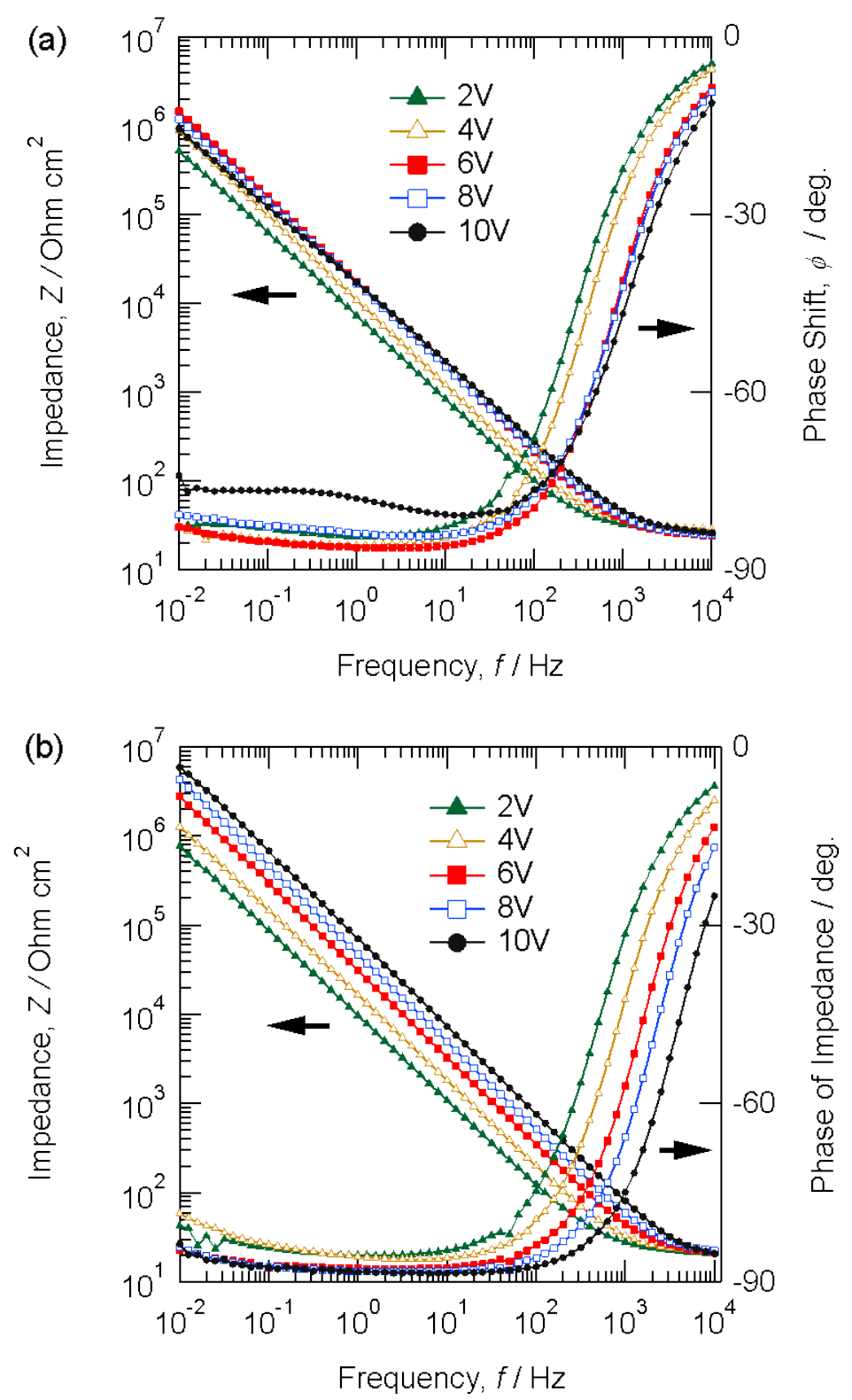

Fig. 5 Bode diagrams of the sputter-deposited (a) Ti and (b) Ti-7 at\% Si columnar films anodized at several formation voltages in $0.1 \mathrm{~mol} \mathrm{dm}^{-3}$ ammonium pentaborate electrolyte at $293 \mathrm{~K}$ for $1.8 \mathrm{ks}$. The diagrams were obtained in $0.1 \mathrm{~mol} \mathrm{dm}^{-3}$ ammonium pentaborate electrolyte at $283 \mathrm{~K}$. 


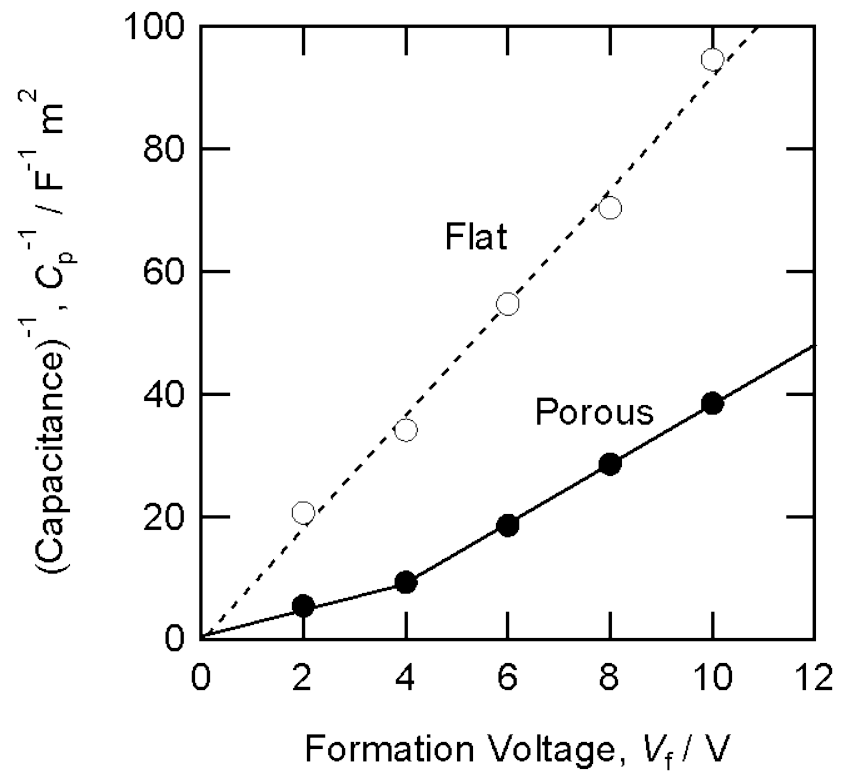

Fig. 6 Correlation between the formation voltage and the reciprocal of capacitance of the anodic films formed on the sputter-deposited Ti-7 at\% Si flat and columnar films in $0.1 \mathrm{~mol} \mathrm{dm}^{-3}$ ammonium pentaborate electrolyte at $293 \mathrm{~K}$ for $1.8 \mathrm{ks}$. 


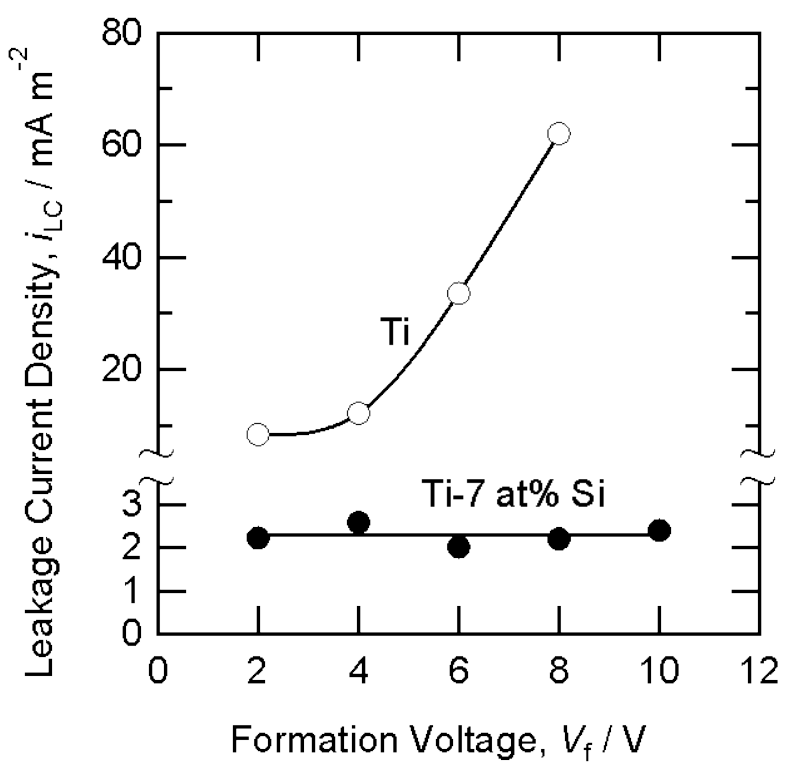

Fig. 7 Change in the leakage current density with formation voltage for the sputter-deposited Ti and Ti-7 at\% Si columnar films anodized at several formation voltages in $0.1 \mathrm{~mol} \mathrm{dm}^{-3}$ ammonium pentaborate electrolyte at $293 \mathrm{~K}$ for $1.8 \mathrm{ks}$. The leakage current density was measured at $70 \%$ of the formation voltage in $0.1 \mathrm{~mol} \mathrm{dm}^{-3}$ ammonium pentaborate electrolyte at $293 \mathrm{~K}$. 


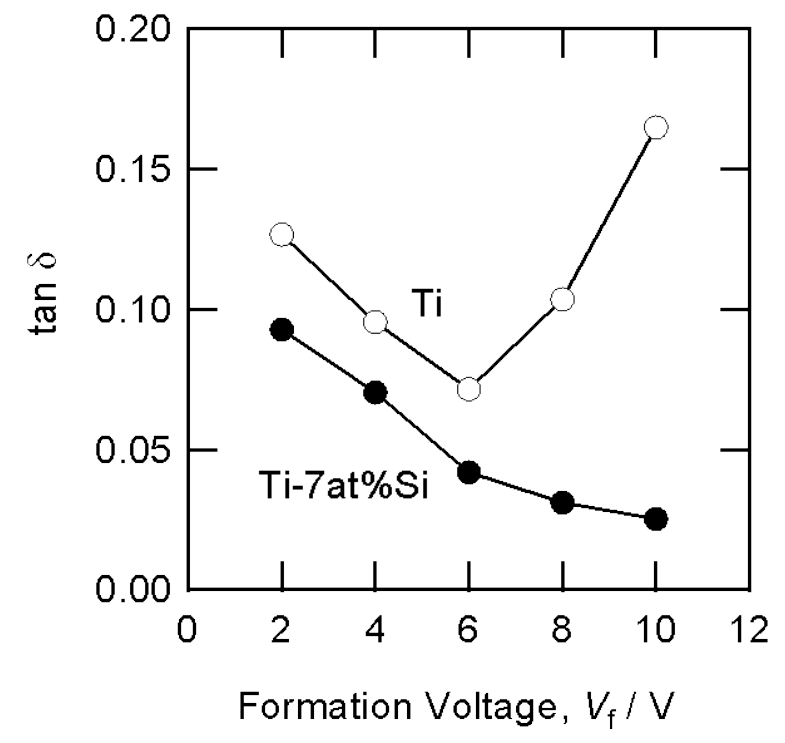

Fig. 8 Change in dielectric loss ( $\tan \delta$ ) with formation voltage for the sputter-deposited Ti and Ti-7 at\% Si columnar films anodized at several formation voltages in $0.1 \mathrm{~mol} \mathrm{dm}^{-3}$ ammonium pentaborate electrolyte at $293 \mathrm{~K}$ for $1.8 \mathrm{ks}$. 